\title{
Ultraviolet Mutagenesis Coupled with Next-Generation Sequencing as a Method for Functional Interrogation of Powdery Mildew Genomes
}

\author{
Mirna Barsoum, ${ }^{1}$ Stefan Kusch, ${ }^{1}$ Lamprinos Frantzeskakis, ${ }^{1}$ Ulrich Schaffrath, ${ }^{2}$ and Ralph Panstruga ${ }^{1, \dagger}$ \\ ${ }^{1}$ RWTH Aachen University, Institute for Biology I, Unit of Plant Molecular Cell Biology, Worringerweg 1, 52056 Aachen, \\ Germany \\ ${ }^{2}$ RWTH Aachen University, Institute for Biology III, Worringerweg 1, 52056 Aachen, Germany \\ Accepted 29 April 2020.
}

\begin{abstract}
Powdery mildews are obligate biotrophic fungal pathogens causing important diseases of plants worldwide. Very little is known about the requirements for their pathogenicity at the molecular level. This is largely due to the inability to culture these organisms in vitro or to modify them genetically. Here, we describe a mutagenesis procedure based on ultraviolet (UV) irradiation to accumulate mutations in the haploid genome of the barley powdery mildew pathogen Blumeria graminis f. sp. hordei. Exposure of $B$. graminis $f$. sp. hordei conidia to different durations of $\mathrm{UV}-\mathrm{C}$ radiation $(10 \mathrm{~s}$ to $12 \mathrm{~min})$ resulted in a reduced number of macroscopically visible fungal colonies. B. graminis f. sp. hordei colony number was negatively correlated with exposure time and the total number of consecutive cycles of UV irradiation. Dark incubation following UV exposure further reduced fungal viability, implying that photoreactivation is an important component of DNA repair in B. graminis f. sp. hordei. After several rounds of UV mutagenesis, we selected two mutant isolates in addition to the parental $B$. graminis $\mathrm{f}$. sp. horde $\mathrm{K} 1$ isolate for whole-genome resequencing. By combining automated prediction of sequence variants and their manual validation, we identified unique $U V$ induced mutations in the genomes of the two isolates. Most of these mutations were in the up- or downstream regions of genes or in the intergenic space. Some of the variants detected in
\end{abstract}

The short-read sequencing data generated in the context of this study (Blumeria graminis $\mathrm{f}$. sp. horde $i$ isolates $\mathrm{K} 1_{\text {Aachen }}$, UV2D, and UV8) can be found at the European Nucleotide Archive (ENA) under project accession PRJEB36770.

Current address for Lamprinos Frantzeskakis: Bayer Crop Science, 890 Embarcadero Dr., West Sacramento, CA 95605, U.S.A.

${ }^{\dagger}$ Corresponding author: R. Panstruga; panstruga @bio1.rwth-aachen.de

Funding: This work was supported by a grant from the Deutsche Forschungsgemeinschaft (DFG)-funded Priority Programme SPP1819 (PA 861/14-1) (Rapid evolutionary adaptation-Potential and constraints) to R. Panstruga, including additional support via a dedicated DFG-funded scheme for Syrian refugees.

*The $\boldsymbol{e}$-Xtra logo stands for "electronic extra" and indicates that supplementary materials are published online.

The author(s) declare no conflict of interest.

() 2020 The American Phytopathological Society genes led to predicted missense mutations. As an additional insight, our bioinformatic analyses revealed a complex population structure within supposedly clonal $B$. graminis f. sp. hordei isolates.

Keywords: Blumeria graminis f. sp. hordei, genome re-sequencing, meta-population, powdery mildew, UV mutagenesis, variant calling

Powdery mildew fungi (phylum Ascomycota, order Erysiphales) infect about 10,000 species of angiosperms (9,000 dicotyledonous and 650 monocotyledonous species [Braun and Cook 2012]). This makes them a major concern in agri- and horticulture, causing notorious plant diseases (Dean et al. 2012). Little is known about the requirements for pathogenicity of this class of phytopathogens at the molecular level, mainly because of their obligate biotrophic lifestyle that, so far, renders them recalcitrant for in vitro cultivation. Additionally, suitable protocols for the genetic manipulation (transformation) of this group of organisms are lacking to date, preventing transgene expression and targeted or nontargeted gene knockouts by insertional mutagenesis, which could form the basis for reverse genetic analysis. So far, Agrobacterium tumefaciens-mediated transformation of the cucurbit powdery mildew Podosphaera xanthii has been suggested as a potent tool for genetic manipulation. However, the transgenes were not stably maintained in the absence of selection pressure (Martínez-Cruz et al. 2017). Apart from transformation, host-induced gene silencing has been used as a tool for the functional analysis of powdery mildew genes (Nowara et al. 2010; Pliego et al. 2013). The technique, though promising, has its limitations since transkingdom gene silencing efficiencies are unpredictable and variable.

With the advent of next- and third-generation sequencing technologies, the number of sequenced genomes of phytopathogens in general and powdery mildew fungi in particular is increasing rapidly (Barsoum et al. 2019). Detailed comparative analysis of the haploid genome sequences of many powdery mildew species revealed that their average genome size is approximately four times larger than those of other filamentous ascomycetes sequenced to date, i.e., about 120 to $170 \mathrm{Mb}$ versus about 35 to $40 \mathrm{Mb}$, respectively (Frantzeskakis et al. 2018b; Jones et al. 2014; Mohanta and Bae 2015; Müller et al. 2019; Spanu et al. 2010; Wicker et al. 2013; Wu et al. 2018). However, they have a comparatively low number of annotated 
protein-coding genes (between 6,000 and 8,500) considering their large genome sizes (Frantzeskakis et al. 2018b; Jones et al. 2014; Müller et al. 2019; Spanu et al. 2010; Wicker et al. 2013; Wu et al. 2018). While the large-scale genomic organization of these fungi has been explored recently (Frantzeskakis et al. 2018b; Müller et al. 2019), the next major challenge will be to assign biological functions to the genes harbored by these genomes.

Blumeria graminis f. sp. hordei is a representative of monocotinfecting powdery mildew fungi that exclusively colonizes barley (Hordeum vulgare). The haploid genome of the $B$. graminis f. sp. hordei reference isolate DH14 encodes approximately 700 candidate secreted effector proteins (CSEPs) that are characterized by the presence of an amino-terminal secretion signal and the lack of significant sequence similarity to other proteins (Frantzeskakis et al. 2018b; Pedersen et al. 2012). Since the vast majority of the CSEPs do not have any recognizable functional domain, their cellular activities and host targets remain largely elusive. Only a few $B$. graminis f. sp. hordei CSEPs have been functionally characterized to date, and the respective studies relied, to a large extent, on transient gene expression in the host plant (Ahmed et al. 2015; Lu et al. 2016; Pennington et al. 2019; Saur et al. 2019; Schmidt et al. 2014). At present, it is unknown (not only for powdery mildews in general and $B$. graminis f. sp. hordei in particular but also for most other phytopathogens) which proportion of the effector arsenal and which other "core" genes of the parasite are indeed required to sustain pathogenicity. In many organisms, including some fungal pathogens, functional studies have been performed based on targeted or nontargeted knockout mutagenesis in either single genes, gene clusters, or both (Ben-Amar et al. 2016; Brefort et al. 2014; Wang and Coleman 2019). Identifying mutations that either change or abrogate gene functions is a key step to discriminate between dispensable and indispensable ("essential") genes in the genome of a given organism (Kobayashi et al. 2003). This approach may help to elucidate further the molecular basis of compatible and incompatible host-pathogen interactions.

Due to the inaccessibility of powdery mildews and other obligate biotrophs to conventional reverse genetic analysis, alternative approaches must be considered for these organisms to explore gene functions. These may comprise the analysis of natural genetic variation or induced mutagenesis. The former approach has been used to identify avirulence genes in $B$. graminis by one or both genetic mapping and association analysis (Bourras et al. 2015, 2019; Lu et al. 2016; Praz et al. 2017; Saur et al. 2019). Regarding the latter approach, both ultraviolet (UV) light and alkylating chemicals such as ethyl methyl sulfonate (EMS) are powerful mutagens that can be applied exogenously and are suitable for forward genetics (Godfroy et al. 2015; Hilton et al. 2016; Sherwood et al. 1991). However, UV radiation has the advantage of the ease of application and bearing essentially no risk for the experimenter. It has been recently used in combination with whole-genome sequencing to identify mutants in the filamentous marine brown alga genus Ectocarpus (Godfroy et al. 2015) and the unicellular green alga genus Chlamydomonas (Hilton et al. 2016).

UV radiation is classified into three categories according to the respective wavelength: UV-A (320 to $400 \mathrm{~nm}$ ), UV-B (290 to $320 \mathrm{~nm})$, and UV-C (<290 nm), with the energy-rich UV-C, covering the absorption maximum of DNA, being the most potent mutagen (Suthaparan et al. 2018). UV produces DNA damage via either a direct or an indirect mechanism. The direct mechanism affects two adjacent pyrimidines (thymines or cytosines), whereby a cyclobutane ring that links the two pyrimidines (cyclobutane pyrimidine dimers [CPDs]) is formed. The indirect mechanism leads to oxidative mutations through the production of reactive oxygen species (ROS). ROS can attack DNA and can cause oxidative base damage (Ikehata and Ono 2011). Two models have been proposed for the fixation of UV-induced mutations during DNA replication: i) "error-free" bypass of deaminated cytosine-containing CPDs by DNA polymerase $\eta$, and ii) "error-prone" bypass, which involves misinsertion and (mis-)extension steps by multiple DNA polymerases (Ikehata and Ono 2011).

The obligate biotrophic nature of $B$. graminis f. sp. hordei renders the generation and maintenance of mutants more challenging compared with many other fungi that can be grown axenically on artificial media. An earlier study revealed it is possible to induce mutations by EMS in B. graminis f. sp. hordei, resulting in morphological and virulence variants (Sherwood et al. 1991). Similarly, it has been shown recently that EMS is able to cause mutations at multiple sites in the genome of the obligate biotrophic rust fungus Puccinia striiformis f. sp. tritici, which, in part, caused a change in the virulence spectrum of the pathogen (Li et al. 2019). Godfroy and coworkers (2015) reported that UV irradiation generated a greater number of genetic lesions than EMS in the case of the marine alga genus Ectocarpus, with more than 400 mutations being detected in the genomes of the mutagenized individuals. The results of this study, therefore, suggest that UV mutagenesis is suitable for approaches that require a high density of mutations (Godfroy et al. 2015).

Here, we present a protocol for UV mutagenesis of the barley powdery mildew pathogen $B$. graminis f. sp. hordei. We demonstrate that prolonged exposure to UV light results in lethality, while moderate UV irradiation causes DNA lesions in various parts of the genome, including protein-coding genes. Our analysis further uncovers the complexity of the population structure of supposedly clonal B. graminis f. sp. hordei isolates.

\section{RESULTS}

UV mutagenesis of $B$. graminis f. sp. hordei.

With the aim of inducing mutations for future functional gene profiling, we established an experimental procedure to explore the effect of UV exposure on B. graminis f. sp. hordei viability. To this end, we initially subjected barley leaves with profusely sporulating $B$. graminis f. sp. hordei colonies (isolate $\mathrm{K} 1_{\text {Aachen }}$ ) to various durations of UV-C irradiation ( 10 or $30 \mathrm{~s}$ or $1,2,4,8$, or $12 \mathrm{~min}$ ) (detailed UV light dosage is provided below) and subsequently transferred the UV-exposed conidia to fresh barley leaves for the development of new fungal colonies (Fig. 1). We observed that the number of resulting macroscopically visible $B$. graminis f. sp. hordei colonies occurring at 7 days postinoculation was negatively correlated with increasing UV exposure time, as judged by a semiquantitative scoring of macroscopically visible fungal colonies. In comparison with the negative control (not subjected to UV treatment), there was almost no reduction in colony number in the case of the 10-s sample and only a small reduction in the 30-s and 1-min samples. By contrast, only a few colonies were left after 12 min of UV irradiation, while the other samples $(2,4$, and $8 \mathrm{~min}$ ) showed a gradual reduction in B. graminis $\mathrm{f}$. sp. hordei colony quantities (Fig. 2). We conclude that excessive UV exposure results in lethality, whereas moderate exposure times ( 2 to $8 \mathrm{~min}$ ) appear to cause mutations that partly affect one or both fungal viability and pathogenicity. In order to accumulate UV-induced mutations, we iteratively repeated this procedure for several cycles by exposing $B$. graminis $\mathrm{f}$. $\mathrm{sp}$. hordei colonies that newly developed after the first round of UV exposure again to the same duration of UV-C irradiation as before. After the third cycle of UV exposure for $12 \mathrm{~min}$, no colonies appeared. Therefore, we omitted the 10-s and 1-min (effect too small) as well as the 12-min (effect too strong) periods from the fourth round of UV irradiation onwards. We 
also performed sporadic microscopic inspection of the mutagenized B. graminis f. sp. hordei strains, starting after the fourth round of UV irradiation. However, unlike the previously reported EMS mutagenesis of B. graminis f. sp. hordei (Sherwood et al. 1991), we did not observe any obvious morphological phenotypes, such as aberrant conidia shapes, altered pigmentation, or changed colony morphology.

As an extension of the standard setup, we introduced a period of dark incubation (for about $16 \mathrm{~h}$ ) after the UV exposure and prior to the inoculation of the conidia on fresh plants from the fourth round onwards. This modification was meant to explore the potential contribution of photolyase to the repair of UVinduced DNA lesions in the presence of visible light - a process known as photoreactivation (Rastogi et al. 2010). A further reduction in $B$. graminis $\mathrm{f}$. $\mathrm{sp}$. hordei viability and pathogenicity was observed in both experimental series (with or without dark incubation), with even more pronounced effects in the case of the respective dark-incubated samples (Fig. 2). No colonies were found after $8 \mathrm{~min}$ of UV irradiation in combination with dark incubation. Therefore, the $8 \mathrm{~min}$ with dark incubation condition was also omitted in the following cycles of UV exposure. Even without dark incubation, after the sixth round of UV treatment for $8 \mathrm{~min}$, only three colonies survived (Fig. 2). One of these was picked for mass propagation, which was first performed at a smaller scale on detached leaves in petri dishes and, later, at larger scale on intact barley plants in sealed glass jars. This isolate was termed UV8. Similarly, after the seventh UV treatment for 2 min (thereof including four in combination with subsequent dark incubation), only a few colonies survived. One of them was likewise picked for mass propagation as described before. This isolate was termed
UV2D. Both UV2D and UV8 showed normal conidia and colony morphology (Supplementary Fig. S1A) and did not differ regarding their virulence spectrum from their parental isolate $\mathrm{K} 1_{\text {Aachen }}$ (Supplementary Fig. S1B). The latter was judged from the entry rates of these isolates on four different plant genotypes exhibiting different levels of disease susceptibility and resistance: barley wild-type plants (cv. Margret, basal defense), a barley line with race-specific resistance to $\mathrm{K} 1_{\text {Aachen }}$ (P01, carrying the Mlal resistance gene [Kølster et al. 1986]), a barley mlo mutant (mlo-3, conferring broad-spectrum resistance [Büschges et al. 1997]), and a wheat cultivar (exhibiting nonhost resistance to $B$. graminis $\mathrm{f}$. sp. hordei [Delventhal et al. 2017]).

\section{Whole-genome resequencing and variant calling.}

Conidia of isolates UV2D and UV8 as well as the respective parental strain $\left(\mathrm{K} 1_{\text {Aachen }}\right)$ were collected weekly and were stored at $-80^{\circ} \mathrm{C}$ to bulk up fungal biomass for genomic DNA extraction and whole-genome resequencing. $\mathrm{K} 1_{\text {Aachen }}$ is a clonal lineage of B. graminis $\mathrm{f}$. sp. hordei isolate K1 (Hinze et al. 1991) that had been propagated at RWTH Aachen University for about 7 years at the beginning of the experiment. It is supposed to be virtually identical to its sister lineage $\mathrm{K} 1_{\text {Cologne }}$ (in parallel maintained at the Max Planck Institute for Plant Breeding Research in Cologne), for which Illumina shortread sequences had been generated in 2012 (Maekawa et al. 2012).

After collecting conidiospores corresponding to a volume of around $2 \mathrm{ml}$ from each of the three genotypes, we performed extraction of high-molecular weight DNA and assessed its quantity and quality both spectrophotometrically and fluorometrically.
Inoculation of soil-grown barley plants with $B g h$

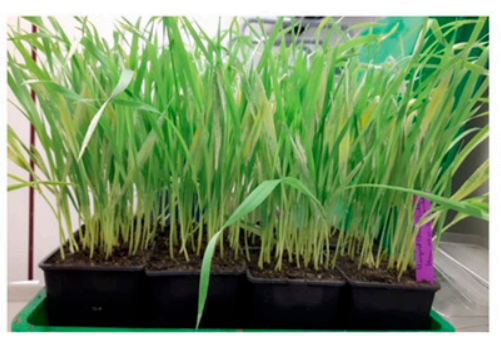

5 days

$\square$

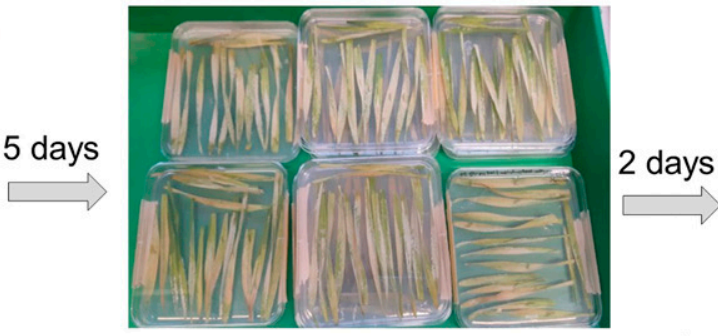

Placement of Bgh-colonized leaves on medium in petri dishes

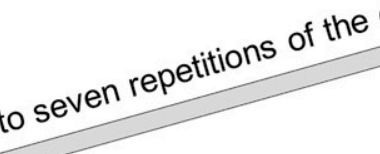

$2 \min$
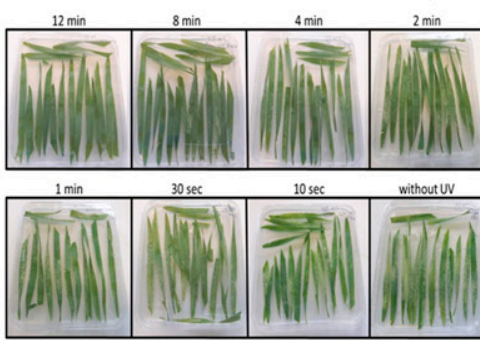

Placement of Bgh-colonized leaves on medium in petri dishes

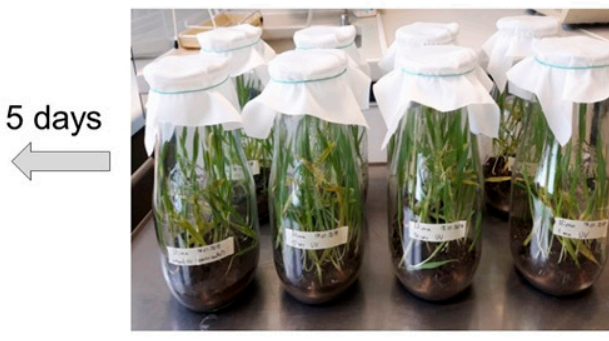

Sealing the jars with gauze
Exposure of inoculated detached leaves to various durations of UV

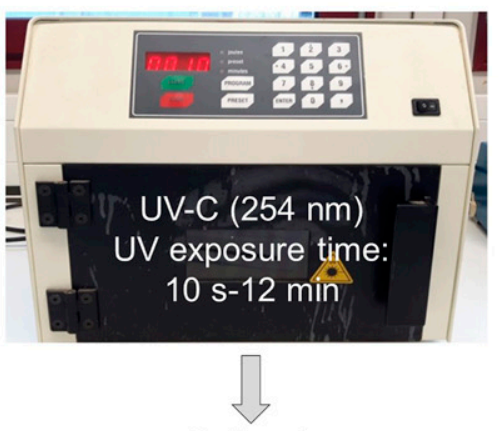

Optional: Dark incubation (ca. 16 h)

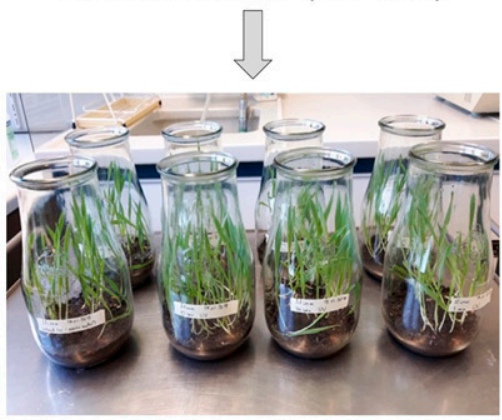

Transfer of conidiospores from detached leaves on barley plants grown in glass jars

Fig. 1. Workflow illustrating ultraviolet (UV) mutagenesis of Blumeria graminis f. sp. hordei $(B g h)$ conidia. The photographs illustrate the main steps of the procedure. 
Agarose gel electrophoresis additionally confirmed the integrity of the genomic DNA samples. These were subsequently subjected to Illumina short-read sequencing, returning approximately 131, 106, and 96 million of 150-bp paired-end reads for $\mathrm{UV} 2 \mathrm{D}, \mathrm{UV} 8$, and $\mathrm{K} 1_{\text {Aachen }}$, respectively. We used these as well as preexisting Illumina short-read sequences for the B. graminis f. sp. hordei isolates DH14
(Frantzeskakis et al. 2018b) and $\mathrm{K} 1_{\text {Cologne }}$ (Maekawa et al 2012) for mapping to the haploid chromosome arm-scale reference genome of the isolate DH14 (Frantzeskakis et al. $2018 \mathrm{~b}$ ). In each case, approximately $85 \%$ of the reads mapped to the DH14 assembly, which we deemed appropriate for a complex eukaryotic genome with many repetitive sequences. The mapped reads resulted in about 75-fold (UV2D, UV8, and
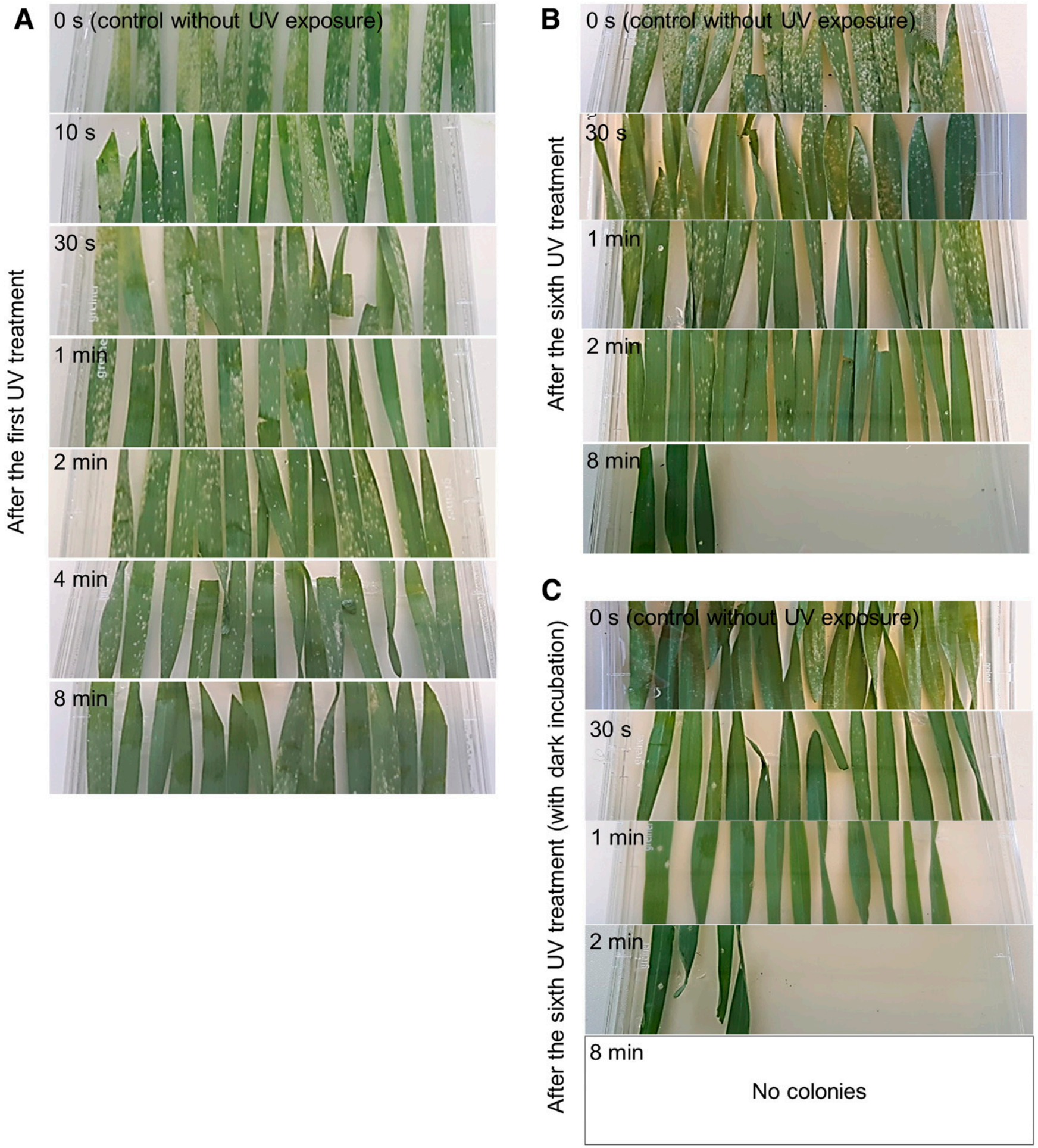

Fig. 2. Ultraviolet (UV) exposure limits Blumeria graminis f. sp. hordei viability and pathogenicity. The photographs show the infection phenotypes of barley leaves inoculated with B. graminis f. sp. hordei conidia that were exposed for various durations of UV-C light as indicated. A, Infection phenotypes after the first round of UV treatment. B, Infection phenotypes after the sixth round of UV treatment (without dark incubation). C, Infection phenotypes after the sixth round of UV treatment, three thereof with subsequent dark incubation following UV exposure. Only leaves harboring macroscopically visible $B$. graminis f. sp. hordei colonies were photographed. 
$\mathrm{K} 1_{\text {Aachen }}$ ), 50-fold (DH14, [Frantzeskakis et al. 2018b]), and

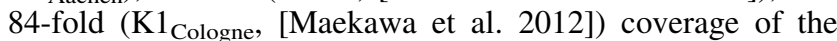
B. graminis f. sp. hordei genome.

We deployed three different bioinformatic tools for variant calling from the respective de-duplicated bam files, which were GATK (McKenna et al. 2010), the mpileup function of Samtools (Li et al. 2009), and Freebayes (Garrison and Marth 2012). As these tools are based on different algorithms, they yielded different numbers of raw variants. These were in a similar range of about 177,000-293,000 for $\mathrm{K} 1_{\text {Aachen }}, \mathrm{K} 1_{\text {Cologne, }}$ UV2D and UV8 as well as about 12,000-30,000 for DH14 (all values relative to the DH14 reference genome [Table 1]). All three tools consistently returned higher numbers of raw variants for the UV-mutagenized isolates UV2D and UV8 compared with the two versions of the parental isolate $\mathrm{K} 1$. This difference was in the range of about 7,000-14,000 more raw variants identified for UV2D and UV8 in comparison with $\mathrm{K} 1_{\text {Aachen, }}$ and in the range of about 35,000-50,000 more raw variants discovered for UV2D and UV8 compared with $\mathrm{K} 1_{\text {Cologne. }}$ Filtering for high confidence variants (details can be found on GitHub) drastically reduced the respective absolute values and also, in part, the difference between $\mathrm{K} 1_{\text {Aachen }}$ and one or both UV8 and UV2D but retained a clear difference between $\mathrm{K} 1_{\text {Cologne }}$ and one or both UV8 and UV2D (in the range of about 18,000 to 33,000 more variants in the UV-mutagenized isolates [Table 1]). Notably, in the case of all three bioinformatic tools, the number of variants for $\mathrm{K} 1_{\text {Aachen }}$ was higher than the number of variants for $\mathrm{K} 1_{\text {Cologne, }}$, even after filtering. Additionally, a remarkable number of variants remained in the case of $\mathrm{DH} 14$ after filtering (about 2,000 to 8,000, depending on the bioinformatic tool [Table 1]).

\section{Visual inspection of predicted sequence variants reveals a complex population structure of the parental B. graminis f. sp. hordei $\mathrm{K} 1$ isolate.}

We took advantage of the Integrated Genome Viewer (IGV) to visualize and validate exemplarily some of the predicted genomic variants identified in the five $B$. graminis f. sp. horde $i$ isolates in comparison with the DH14 reference sequence (Table 1). Unexpectedly, we found extraordinary genomic intra- and interpopulation sequence variation within and between both populations of $B$. graminis $\mathrm{f}$. $\mathrm{sp}$. hordei isolate $\mathrm{K} 1$ ( $\mathrm{K} 1_{\text {Aachen }}$ and $\mathrm{K} 1_{\text {Cologne }}$ ), exemplified by numerous single nucleotide polymorphisms (SNPs). Most of these SNPs were monoallelic, representing a single type of nucleotide difference per site between the three genomes. SNP allele frequency was variable and ranged from a few reads to all reads for a given nucleotide position (Fig. 3). We did not note any conspicuous clustering of these SNPs in particular genomic regions. Based on these observations, we conclude that both B. graminis $\mathrm{f}$. $\mathrm{sp}$. hordei $\mathrm{K} 1$ populations are not clonal but represent mixtures of numerous allelic variants (haplotypes), which probably emerged within a comparatively short time (within a few years) during asexual propagation on susceptible barley cultivars after separation of $\mathrm{K} 1_{\text {Aachen }}$ and $\mathrm{K} 1_{\text {Cologne. }}$. This is seemingly also true for the B. graminis $\mathrm{f}$. sp. horde $i \mathrm{DH} 14$ reference isolate, for which, likewise, a number of well-supported intrapopulation SNPs were found by alignment of the individual sequence reads to the reference sequence (Supplementary Fig. S2).

To assess the frequency distribution of allelic variants within the $B$. graminis f. sp. hordei isolates at a genome-wide level, we analyzed the number of reads supporting any SNPs in comparison with the DH14 reference genome in presumed singlecopy sequences (genes and their immediate 5-kb up- and downstream regions). In the case of isolate DH14, we found a broad distribution of SNP frequencies with most of the SNPs supported by $<50 \%$ of the Illumina reads, indicating the lowlevel presence of these SNPs within the DH14 population (Fig. 4A). By contrast, we noticed a bimodal distribution of SNP frequencies for isolates $\mathrm{K} 1_{\text {Aachen }}$ and $\mathrm{K} 1_{\text {Cologne. }}$ In addition to a substantial proportion of SNPs, similarly to DH14, supported by $<50 \%$ of the Illumina reads, a considerable number of SNPs in these two isolates is supported by 90 to $99 \%$ of the reads, indicating (near) homozygosity at the population scale (Fig. 4B and $\mathrm{C}$ ). These SNPs likely represent fixed alleles that discriminate $B$. graminis $\mathrm{f}$. sp. hordei isolate $\mathrm{K} 1$ from $\mathrm{DH} 14$.

\section{Unique sequence variants in UV-mutagenized B. graminis f. sp. hordei isolates UV2D and UV8.}

After initial variant calling, we determined the number of unique variants in UV2D (not present in UV8) and unique variants in UV8 (not present in UV2D) before and after filtering (Tables 2 and 3). When we used GATK, the number of unique variants was similar in both cases (when the unique variants were determined before or after filtering) because GATK keeps the filtered variants in the variant call format (vcf) file and only marks them as filtered. Accordingly, GATK calculated 1,583 and 1,428 unique SNPs as well as 1,617 and 1,616 unique insertions and deletions (INDELs) in UV2D and UV8, respectively (Tables 2 and 3). However, the numbers were different when we used Samtools mpileup or Freebayes for analysis of the same dataset because the filtered variants are deleted from the vcf file after filtering. Consequently, these two tools identified fewer unique variants in both UV2D and UV8

Table 1. Number of raw and filtered sequence variants in various Blumeria graminis $\mathrm{f}$. sp. hordei isolates in comparison with the $B$. graminis $\mathrm{f}$. sp. hordei $\mathrm{DH} 14$ reference genome

\begin{tabular}{|c|c|c|c|c|c|c|c|}
\hline Tool & Isolate & Raw variants & Raw SNPs ${ }^{a}$ & Filtered SNPs & Raw INDELs & Filtered INDELs & Filtered variants \\
\hline \multirow[t]{5}{*}{ GATK } & $\mathrm{K} 1_{\text {Cologne }}$ & 177,226 & 166,506 & 129,040 & 10,720 & 10,667 & \\
\hline & UV2D & 212,447 & 197,600 & 148,038 & 14,847 & 14,782 & \\
\hline & UV8 & 211,254 & 196,428 & 148,544 & 14,826 & 14,789 & \\
\hline & DH14 & 12,238 & 7,034 & 3,174 & 5,174 & 5,163 & \\
\hline & $\mathrm{K} 1_{\text {Aachen }}$ & 203,830 & 189,791 & 148,032 & 14,015 & 13,953 & \\
\hline \multirow[t]{5}{*}{ Mpileup } & $\mathrm{K} 1_{\text {Cologne }}$ & 176,954 & & & & & 102,951 \\
\hline & UV2D & 212,538 & & & & & 121,455 \\
\hline & UV8 & 210,730 & & & & & 121,341 \\
\hline & DH14 & 12,120 & & & & & 1,851 \\
\hline & $\mathrm{K} 1_{\text {Aachen }}$ & 203,069 & & & & & 121,054 \\
\hline \multirow[t]{5}{*}{ Freebayes } & $\mathrm{K} 1_{\text {Cologne }}$ & 243,295 & & & & & 147,192 \\
\hline & UV2D & 293,381 & & & & & 172,027 \\
\hline & UV8 & 290,540 & & & & & 170,850 \\
\hline & DH14 & 30,213 & & & & & 6,009 \\
\hline & $\mathrm{K} 1_{\text {Aachen }}$ & 279,478 & & & & & 176,163 \\
\hline
\end{tabular}

${ }^{\text {a }}$ SNPs = single nucleotide polymorphisms. 
when the unique variants were called from the raw variant list and subsequently filtered (Tables 2 and 3 ).

Using IGV, we exemplarily visualized the unique variants called and again found considerable genomic variation conditioned by intrapopulation SNPs within a single mutant isolate, which resulted in calling of many false-positive unique variants in UV2D and UV8 (Fig. 3, box 2). We therefore evaluated all predicted unique variants by manual inspection in IGV. The called unique variants were designated as "validated unique variants" when they were present in $>95 \%$ of the reads of the respective strain and in $<5 \%$ of the other strain (Figs. 5 and 6 ; note that the $<5 \%$ inconsistencies are likely due to sequencing errors or ambiguous mapping of individual short reads). Based on this procedure, we could validate 22 unique variants in isolate UV8 and 125 unique variants in isolate UV2D (Table 4; Supplementary Tables S1, S2, S3, S4, S5, and S6). In addition, we found 51 validated unique variants in $\mathrm{K} 1_{\text {Aachen }}$ compared with $\mathrm{K} 1_{\text {Cologne }}$ (Fig. 3; Supplementary Tables S7, S8, S9, S10, and S11). We did not find any validated joint mutations in UV2D and UV8, suggesting there is no obvious "UV mutagenesis hotspot" in the B. graminis f. sp. hordei genome.

The manually validated sequence variants in UV2D or UV8 are spread throughout the genome and do not cluster in a particular genomic section, as indicated by the respective scaffold
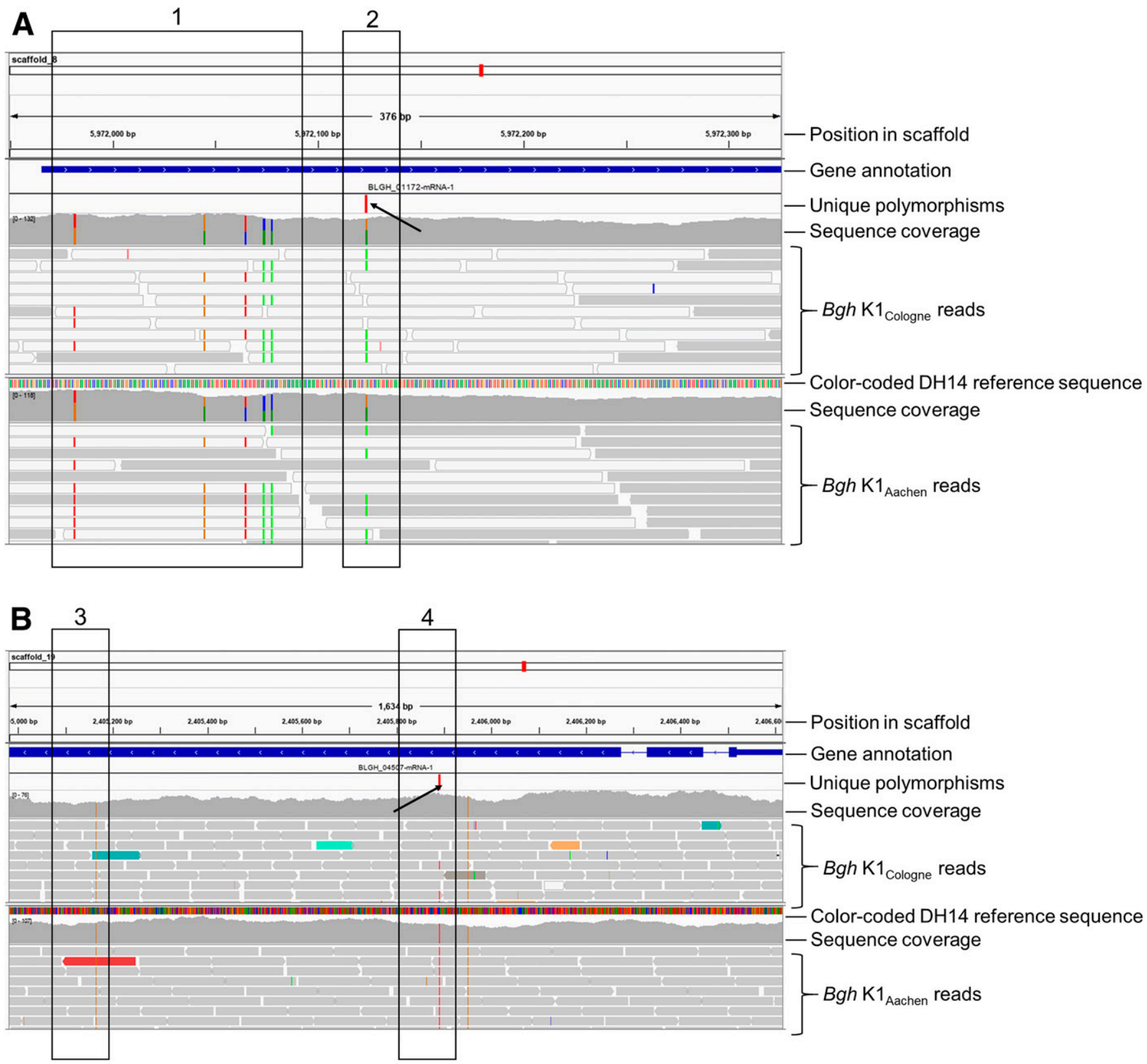

Fig. 3. Integrative Genomics Viewer (IGV) screenshot showing genomic variation within the Blumeria graminis f. sp. hordei $\mathrm{K} 1_{\mathrm{Cologne}}$ and $\mathrm{K} 1_{\mathrm{Aachen}} \mathrm{isolates}_{\text {. }}$ The screenshot visualizes Illumina reads (colored according to the IGV alignment track) that were mapped against the chromosome arm-level genome sequence of the $B$. graminis f. sp. hordei DH14 reference isolate in either A, gene BLGH_01172, localized on scaffold 8, or B, gene BLGH_04507, localized on scaffold 10. Boxes highlight examples of single nucleotide polymorphisms (SNPs) (variants in comparison with the DH14 reference sequence are indicated by colored vertical marks in the sequence coverage and reads panels: A, green; C, blue; G, orange; T, red). Box 1 shows SNPs that are present in part of the $\mathrm{K} 1_{\text {Cologne }}$ and part of the $\mathrm{K} 1_{\text {Aachen }}$ population. Boxes 2 and 4 show SNPs that are present in part of the $\mathrm{K} 1_{\text {Cologne }}$ and part of the $\mathrm{K} 1_{\text {Aachen }}$ population and erroneously flagged as unique polymorphisms in $\mathrm{K} 1_{\text {Aachen }}$ (false-positives are indicated by arrows). Box 3 shows a SNP that is present in the entire $\mathrm{K} 1_{\text {Cologne }}$ as well as the entire $\mathrm{K} 1_{\text {Aachen }}$ population, indicating a common difference between $B$. graminis $\mathrm{f}$. sp. horde $i$ isolate $\mathrm{K} 1$ and the reference isolate $B$. graminis $\mathrm{f}$. sp. hordei $\mathrm{DH} 14$ 
numbers (Supplementary Tables S1, S2, S3, S4, S5, and S6). Most of them are located in the up- or downstream regions of genes (i.e., less than $5 \mathrm{~kb}$ away from the gene; 49 in UV2D and nine in UV8) (Table 4; Supplementary Tables S3 and S4) or in the intergenic space (i.e., more than $5 \mathrm{~kb}$ away from the gene; 52 in UV2D and nine in UV8) (Table 4; Supplementary Tables S5 and S6). However, we also detected some variants within genes (24 in UV2D and four in UV8) (Table 4; Supplementary Tables S1 and S2), of which few are predicted missense mutations (eight in UV2D and two in UV8) (Table 4; Supplementary Tables S1 and S2). We found no nonsense mutation in this dataset. Of the 147 manually validated unique variants present in UV8 and UV2D, 68 (46\%) represent nucleotide exchanges that are characteristic for UV mutagenesis (Table 5). The vast majority of those $(64$, i.e., $94 \%)$ occurred at dipyrimidine sites, as is typical for UV-induced mutations. Similar to isolates UV2D and UV8, most of the 51 manually validated unique variants in $\mathrm{K} 1_{\text {Aachen }}$ as compared with $\mathrm{K} 1_{\text {Cologne }}$ are in the intergenic space (28) or up- or downstream of genes (16) (Supplementary Tables S9 and S10). Nonetheless, we also detected seven validated unique variants inside genes in this comparison, of which two are missense mutations (Supplementary Table S9).

\section{Natural sequence variants with deleterious effects in B. graminis f. sp. hordei populations.}

The analysis described above refers to sequence variants that are present in $>95 \%$ of the reads of the respective strain, essentially representing mutational events that became fixed in the particular population. To explore whether putative deleterious mutations might exist naturally in part of these $B$. graminis f. sp. hordei populations, we determined sequence variants that are present in $<95 \%$ of the reads and that give rise to potentially deleterious effects, i.e., gain or loss of stop codons, causing frame shifts, or affecting predicted splice junctions. We discovered and manually validated 19 such variants that affect 15 different genes and are represented to various degrees in the five B. graminis f. sp. hordei populations. Most of these natural polymorphisms are either present in all isolates except DH14 (i.e., specific to K1) or in all isolates except $\mathrm{DH} 14$ and $\mathrm{K} 1_{\text {Cologne }}$ (i.e., specific to $\mathrm{K} 1_{\text {Aachen }}$ ) (Supplementary Table $\mathrm{S} 12$ ).

\section{DISCUSSION}

The experimental workflow established in this study allows the evaluation of the effect of UV irradiation of B. graminis f. sp. hordei conidiospores on fungal viability and pathogenesis (Fig. 1). The reduction in the number of macroscopically visible $B$. graminis f. sp. hordei colonies by increasing UV exposure time (Fig. 2) suggests that prolonged UV exposure may lead to a severe mutational load, apparently strongly impairing viability and pathogenicity of the fungal pathogen in our experimental conditions. These results are in line with observations from a previous report in which the effect of UV irradiation to control Oidium neolycopersici, the causal agent of powdery mildew disease in tomato, was explored. In this study, short UV-C treatment (for $1 \mathrm{~min}$ ) reduced fungal germination by 20 to $40 \%$ compared with the control, while longer exposure to UV (for 12 to $24 \mathrm{~min}$ ) abolished germination nearly completely (Suthaparan et al. 2016). In our setup, additional cycles of UV treatment led to further reduction in B. graminis $\mathrm{f}$. $\mathrm{sp}$. hordei viability and pathogenicity (with or without dark incubation), with even more pronounced effects in the respective dark-incubated samples (Fig. 2). This finding suggests that consecutive rounds of UV exposure may introduce additional mutations, thereby likely increasing the total mutational load (mutation accumulation). However, we cannot exclude the possibility that individual spores escaped efficient mutagenesis due to position effects in one or the other round, e.g., by protection on the lower leaf side or shielding by neighboring conidiophores within a fungal colony.

It is well-known that eukaryotic cells possess specialized repair systems for correcting UV radiation-induced DNA damage, and one of them is the light-dependent photolyase. Photolyases are DNA-repair enzymes that require visible light for their activation and activity, which mainly involves the conversion of CPDs to unlinked pyrimidines in a process termed photoconversion (Sinha and Häder 2002). Only after the

Table 2. Number of unique variants in Blumeria graminis f. sp. hordei isolates UV2D and UV8 after filtering of the raw variants and subsequent variant calling

\begin{tabular}{llccc}
\hline Tool & Isolate & Unique variants & Unique SNPs & Unique INDELs \\
\hline GATK & UV2D & & 1,583 & 1,617 \\
& UV8 & & 1,428 & 1,616 \\
Mpileup & UV2D & 3,511 & & \\
& UV8 & 3,397 & & \\
Freebayes & UV2D & 4,149 & & \\
& UV8 & 2,972 & & \\
\hline
\end{tabular}

a SNPs = single nucleotide polymorphisms.
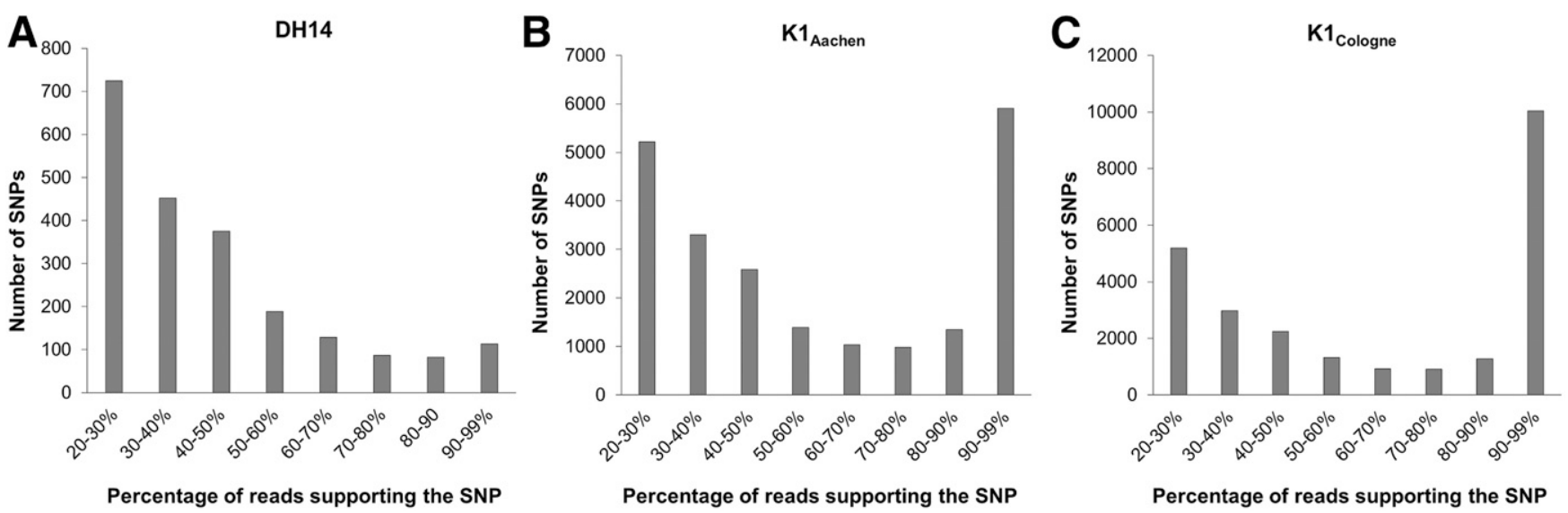

Fig. 4. Single nucleotide polymorphism (SNP) frequency within Blumeria graminis f. sp. hordei isolates $\mathrm{DH} 14$, $\mathrm{K} 1_{\mathrm{Aachen}}$, and $\mathrm{K} 1_{\mathrm{Cologne}}$. A, The number of SNPs ( $y$ axis) in comparison with the DH14 reference genome that are supported by a certain percentage of Illumina reads ( $x$ axis) for $B$. graminis $\mathrm{f}$. sp. horde $i$

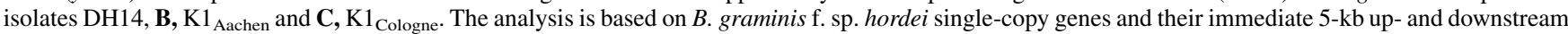
regions, i.e., mostly single-copy sequences. Note that bins 0 to $10 \%$ and 10 to $20 \%$ were omitted because Freebayes considers variants that occur in less than $20 \%$ of the reads as artifacts. 
ablation of these repair systems will the full impact of UV mutagenesis likely become effective. It was shown previously that UV-C irradiation for powdery mildew disease management was considerably more effective when the UV exposure was followed by a period of dark incubation. Results of this study indicated that the repair mechanism will become ineffective if the samples do not receive potential recovery wavelengths (visible light) within $4 \mathrm{~h}$ from the effective UV treatment (Suthaparan et al. 2018). Similarly, UV-C irradiation followed by a dark period resulted in a strong reduction of fungal colonization of leaf discs by Podosphaera aphanis, the strawberry powdery mildew pathogen (Janisiewicz et al. 2016). In our experimental conditions, the number of macroscopically visible colonies was obviously lower after dark incubation compared with the same UV-C exposure time without dark incubation (Fig. 2). This finding suggests that the lack of photoreactivation by dark incubation of the UV-exposed strains reduces the DNArepair capacity, additionally enhancing the effect of UV mutagenesis (Fig. 2). The substantially (sixfold) higher number of visually confirmed mutational events in the genome of the dark-incubated isolate (UV2D) compared with the non-dark incubated isolate (UV8) (Table 4) reinforces the notion that, indeed, the process of photoreactivation may modulate the efficiency of UV mutagenesis in $B$. graminis f. sp. hordei. However, these numbers are based on single samples; thus, additional experiments will be necessary to substantiate this proposition.

We noted abundant genomic variation in the haploid $B$. graminis $\mathrm{f}$. $\mathrm{sp}$. hordei isolates $\mathrm{K} 1_{\text {Aachen }}, \mathrm{K} 1_{\text {Cologne, }}$, and $\mathrm{DH} 14$ that was apparently present prior to the UV irradiation experiment. This genomic variation comprises typically monoallelic SNPs that are mostly present in parts of the sequence reads of the isolates at different frequencies, ranging from rare occurrence to full penetrance (Figs. 3 and 4; Supplementary Fig. S1). Although we cannot rule out that some of these variants are artifacts introduced by mis-mapping of Illumina reads to repetitive sequences within the complex B. graminis f. sp. hordei genome, at least some of the SNPs occur in single-copy sequences, i.e., supposedly unique sequences within either genes, the immediate up- and downstream regions, or both. This finding indicates that these $B$. graminis $\mathrm{f}$. $\mathrm{sp}$. hordei isolates are not clonal populations but mixtures of multiple allelic variants, suggesting cryptic genetic diversity, the existence of multiple haplotypes, and a complex (meta-)population structure. These insights are based on a moderate sequence depth, resulting in genome coverage of about 50- to 83-fold, suggesting that the true intrapopulation diversity is likely to be much higher. Since these $B$. graminis f. sp. hordei isolates were, in part, propagated for many years under nonsterile conditions, the detected allelic variants could, in principle, result from $B$. graminis f. sp. hordei contaminations introduced from the outside environment. This is, however, unlikely since genomic variation between isolates is typically considerably higher than the within-isolate genomic variation detected here (compare the results for DH14 and K1 in Table 1, with $<10,000$ filtered variants for the DH14-DH14 comparison and $>100,000$ filtered variants for the $\mathrm{K} 1_{\text {Aachen }^{-}}$
DH14 and $\mathrm{K} 1_{\text {Cologne-DH14 comparisons). In addition, the }}$ monoallelic nature of the vast majority of the SNPs argues against a scenario of one or more external contaminations. Furthermore, our analysis revealed a similar situation (though to a lesser degree) in the UV-mutagenized $B$. graminis f. sp. horde $i$ isolates UV2D and UV8, which are single-colony descendants that were propagated in a sealed environment (glass jars) for a limited amount of time (several weeks or months). We thus assume that the majority of the SNPs detected by our analysis results from spontaneous mutational events that occurred within the populations in the past few weeks, months, or years and that were subsequently transmitted within the populations during asexual propagation on susceptible barley plants. The haploid nature of the $B$. graminis f. sp. hordei genome may facilitate the rapid fixation and spread of mutations within the given populations. Apparently, at least 51 SNPs became fixed in the genome of the $\mathrm{K} 1_{\text {Aachen }}$ population since its separation from the $\mathrm{K} 1_{\text {Cologne }}$ population about 7 years ago (Supplementary Tables S9, S10, and S11), and many more are present at various frequencies within the populations, including DH14 (Fig. 4). Some of these give rise to putative deleterious effects on gene function, namely gains or losses of stop codons, the occurrence of frame shifts, and alterations of intron splice sites. We discovered 19 such mutational events affecting 15 different genes (Supplementary Table S12). These sequence variants seem to be present as balanced polymorphisms in some of the B. graminis f. sp. hordei populations. Since some of the sequence variants may compromise gene function, it could be hypothesized that the respective genes are dispensable for fungal virulence and the completion of the asexual life cycle.

Our findings are reminiscent of the "non-clonality" of bacterial populations, which is well appreciated (Bobay et al. 2015; Shapiro 2016). In unicellular yeast, genomic analysis of mutation accumulation lines revealed rather precise estimates of the rate and spectrum of spontaneous mutations within clonal lineages (Zhu et al. 2014). More recently, an elegant study using an in-vivo barcoding system uncovered unexpected patterns of evolutionary dynamics at high resolution in budding yeast. The authors of this study found waves of adaptation that are driven by the continuous appearance of new mutations that, even at low within-population frequencies, affect lineage fate (Nguyen Ba et al. 2019). However, to our knowledge, comparable data are, at present, not available for filamentous fungi. The lack of precise values regarding population size and generation time precludes similar calculations as in yeast for B. graminis f. sp. hordei on the basis of our data. Nonetheless, our findings imply similar to yeast "real-time" evolution of B. graminis f. sp. hordei during asexual propagation via spontaneously occurring SNPs, which are either maintained as balanced polymorphisms within the population or become fixed alleles at some point. This, together with genomic rearrangements based on (retro-)transposon activity, may form the basis for the proposed rapid evolution of powdery mildew fungi, allowing fast adaptation of the pathogen to new host environments (Frantzeskakis et al. 2018a, 2019, 2020).

Table 3. Number of unique variants in Blumeria graminis f. sp. hordei isolates UV2D and UV8 after variant calling and subsequent filtering

\begin{tabular}{|c|c|c|c|c|c|c|c|}
\hline Tool & Isolate & Unique variants & Unique variants filtered & Unique SNPs ${ }^{\mathbf{a}}$ & Unique SNPs filtered & Unique INDELs & Unique INDELs filtered \\
\hline \multirow[t]{2}{*}{ GATK } & UV2D & & & 7,715 & 1,583 & 1,654 & 1,617 \\
\hline & UV8 & & & 6,543 & 1,428 & 1,633 & 1,616 \\
\hline \multirow[t]{2}{*}{ Mpileup } & UV2D & 10,114 & 1,547 & & & & \\
\hline & UV8 & 8,306 & 1,161 & & & & \\
\hline \multirow[t]{2}{*}{ Freebayes } & UV2D & 21,932 & 325 & & & & \\
\hline & UV8 & 19,091 & 175 & & & & \\
\hline
\end{tabular}

\footnotetext{
${ }^{\mathrm{a}}$ SNPs $=$ single nucleotide polymorphisms.
} 
The limited clonality of the parental $\mathrm{K} 1_{\text {Aachen }}$ population caused severe challenges for the identification of UV-induced genomic variants in the mutagenized isolates by automated bioinformatic pipelines. We noted that, in particular, the order of the steps of variant filtering and calling of unique variants affected the quality of the outcome. We found that, for our dataset, the calling of the unique variants followed by filtering gave superior results (fewer false-positive mutational events) than the opposite order. In addition, depending on the allele frequency of a shared SNP, some variants were recognized in one mutant isolate but not in the other, leading to the falsepositive flagging as a seemingly unique variant (Supplementary Fig. S3). The Freebayes tool was the best of the three tools used to deal with this problem, because it calls the highest number of variants at the raw variant calling step (Table 1).

The number of manually validated variants in UV2D and UV8 is relatively low (125 and 22, respectively) (Table 4). This compares, for example, to 442 mutational events detected upon UV mutagenesis in the marine alga genus Ectocarpus (Godfroy et al. 2015) and up to 900 mutations that were induced in single haploid yeast strains by multiple rounds of EMS mutagenesis (Abt et al. 2016). When considering the genome-wide number of mutational events, the quality of the reference sequence must be considered, as this is one of the key determinants for the accuracy of variant calling pipelines (Ribeiro et al. 2015). The reference genome used here is that of $B$. graminis $\mathrm{f}$. sp. horde $i$ isolate DH14, while the actual parental isolate deployed in the experiment was $\mathrm{K} 1_{\text {Aachen }}-\mathrm{a}$ constellation that further complicates bioinformatic analysis and should be avoided in the future by the establishment of a high-quality long read-based $\mathrm{K} 1_{\text {Aachen }}$ reference genome. Furthermore, a large proportion of the B. graminis f. sp. hordei genome (approximately $74 \%$ ) is comprised of repetitive sequences (Frantzeskakis et al. 2018b; Spanu et al. 2010) for which we cannot reliably detect mutational events, which, in particular, explains the comparatively low number of variants found in the intergenic space. Extrapolating the number of mutations found in the single-copy regions to the entire genome, we can expect around 500

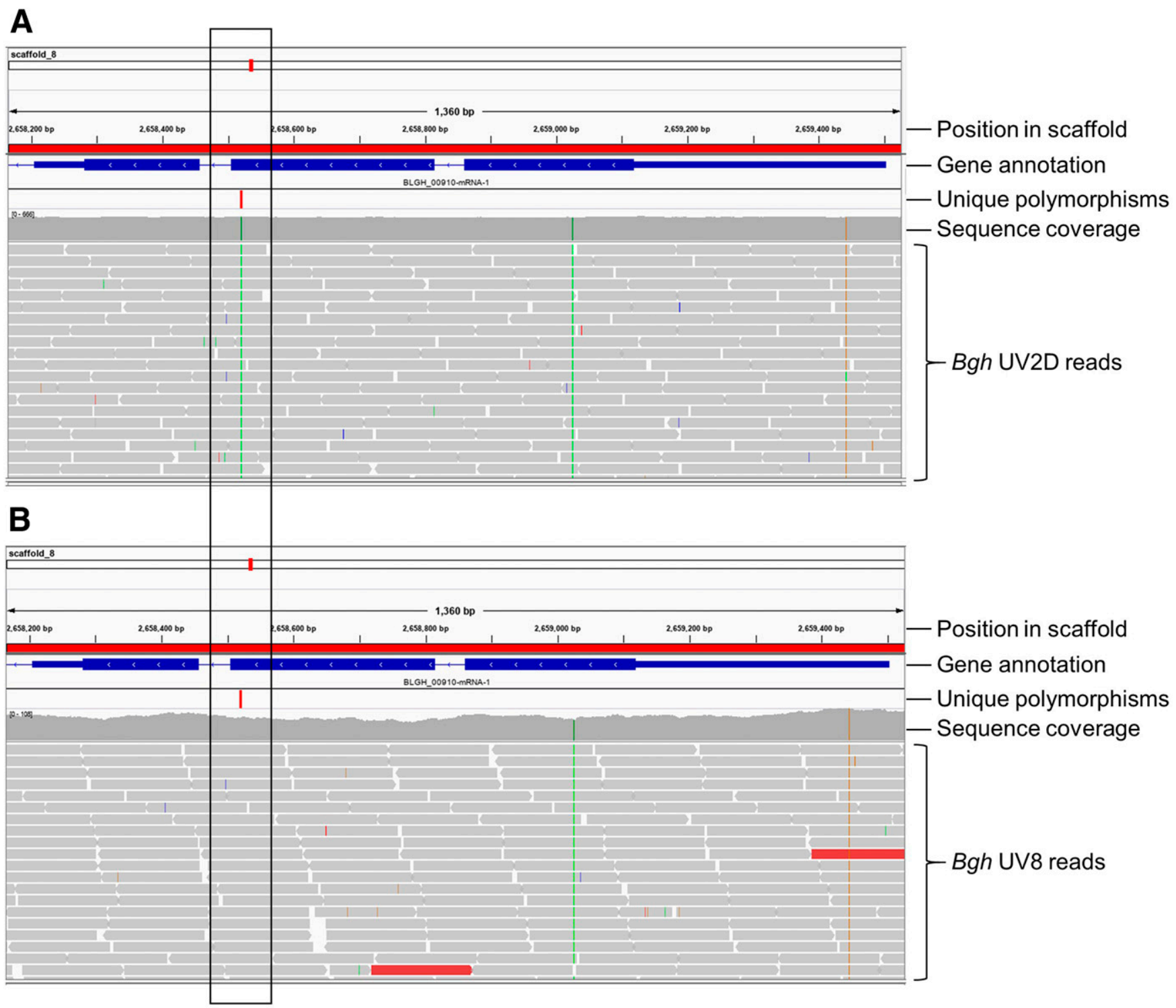

Fig. 5. Integrative Genomics Viewer (IGV) screenshot representing a validated unique variant present in Blumeria graminis f. sp. hordei isolate UV2D (not present in $B$. graminis f. sp. horde $i$ isolate UV8). The screenshot visualizes A, B. graminis $\mathrm{f}$. sp. horde $i \mathrm{UV} 2 \mathrm{D}$ and $\mathbf{B}$, UV8 Illumina reads (colored according to the IGV alignment track) that were mapped against the chromosome arm-level genome sequence of the $B$. graminis f. sp. horde $i$ DH14 reference isolate. A box highlights an example of a single nucleotide polymorphism that exists in gene $B L G H \_00910$ on scaffold 8 in the UV2D isolate (indicated by green vertical marks in the UV2D sequence coverage and reads panels and flagged as a unique polymorphism by the red vertical mark) but not in the UV8 isolate. 
mutations in UV2D and around 90 mutations in UV8 genomewide. At least for UV2D, this number is similar to the value described for UV mutagenesis in genus Ectocarpus (Godfroy et al. 2015). It is also challenging to find the best balance between false-positive and false-negative detection of sequence variants from high-throughput sequencing data using the variant calling tools available to date (Ribeiro et al. 2015). We therefore applied very stringent filtering to remove lowconfidence variants, which led to an around 100-fold reduction in variant candidates (Table 1 compared with Table 3 ). It is conceivable that the very stringent filtering procedure applied in fact resulted in an underestimation of the number of true mutational events in our samples due to the exclusion of so-called false negatives. In the future, other procedures for variant discovery, such as de novo genome assembly followed by whole genome alignment (Potgieter et al. 2020), might be considered as alternatives to the classical alignment-based approach. Another reason possibly accounting for the relatively low number of mutational events discovered in our study is the experimental setup. We co-inoculated the UV-exposed conidia to develop new colonies prior to the next cycle of UV treatment. This procedure possibly led to the recovery of the "fittest" (least impacted) mutagenized isolates. To avoid this in the future, we suggest separating single colonies after each round of UV exposure, propagating them individually, and then applying UV irradiation separately for each. This might avoid losing the weakest (most impacted) mutagenized isolates. Finally, our experimental setup might have selected for spores that escaped from efficient mutagenesis, e.g., due to position effects on the leaf or within the fungal colony as discussed above.

The comparatively low number of mutational events may also explain why we did not find any recognizable phenotypes within the mutant population, even upon microscopic evaluation. This contrasts the outcome of previous EMS-based mutagenesis of $B$. graminis $\mathrm{f}$. sp. hordei, which resulted in the recovery of conidia and hyphae with altered pigmentation, conidia with aberrant shape and premature germination, as well as fungal colonies with altered morphology (Sherwood et al.

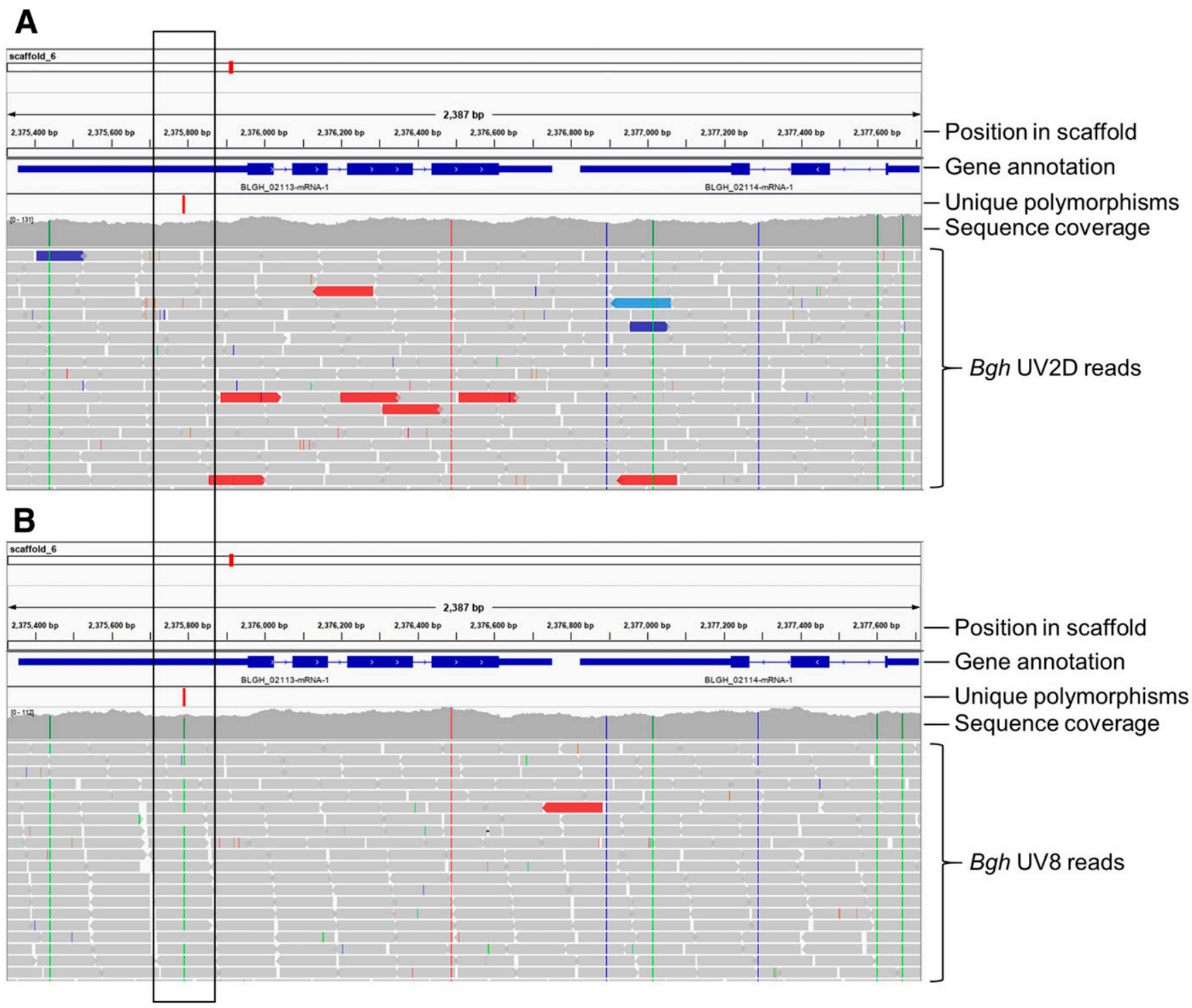

Fig. 6. Integrative Genomics Viewer (IGV) screenshot representing a validated unique variant in Blumeria graminis f. sp. hordei isolate UV8 (not present in $B$. graminis f. sp. horde $i$ isolate UV2D). A, The screenshot visualizes UV2D and B, UV8 Illumina reads (colored according to the IGV alignment track) that were mapped against the chromosome arm-level genome sequence of the B. graminis f. sp. hordei DH14 reference isolate. A box highlights an example of a single nucleotide polymorphism that exists in gene $B L G H \_02113$ on scaffold 6 in the UV8 isolate (indicated by green vertical marks in the UV8 sequence coverage and reads panel and flagged as a unique polymorphism by the red vertical mark) but not in the UV2D isolate. 
1991). This result may indicate that EMS mutagenesis is more potent than UV mutagenesis in $B$. graminis f. sp. hordei but could also simply reflect the limitations of our current experimental setup, as discussed above.

Consistent with data obtained by others (Godfroy et al. 2015), we noted that approximately half of the validated sequence variants discovered in this experiment are SNPs of the C to $\mathrm{T}$ or $\mathrm{G}$ to A type (57 of 125 in UV2D and 11 of 22 in UV8) (Table 5). These are mutations according to the canonical UV signature, typically caused by photochemical DNA damage, which produce mutagenic DNA alterations (e.g., the formation of CPDs [Ikehata and Ono 2011]), with G to A representing the respective event on the complementary DNA strand. The remaining types of nucleotide polymorphisms (55\%) might have been caused by indirect means via UV-induced ROS production (Ikehata and Ono 2011).

In the future, systematic experiments could be performed to identify the optimal mutagenesis strategy for B. graminis f. sp. hordei, e.g., to clarify whether, indeed, multiple rounds of UV exposure lead to the highest mutational load. Moreover, multiple UV-mutagenized B. graminis f. sp. hordei strains can be analyzed by genome resequencing and deep genome-wide shotgun transcript sequencing (RNA-seq). This will reveal mutational events at the genomic level and their corresponding effects at the transcriptome level (e.g., for promoter and intron mutations that may affect transcript levels or correct splicing and mRNA stability). Individual B. graminis f. sp. hordei mutant strains can then be analyzed for genes or transcripts that show clear evidence for a loss of function (e.g., premature stop codons or mis-splicing, frame shifts or the absence of transcript). The analysis of multiple such mutant strains will provide a global overview about which genes are dispensable and which are seemingly essential for $B$. graminis f. sp. hordei pathogenesis (Supplementary Fig. S4). This approach will thus allow the functional profiling of the genome of a fungal phytopathogen with an obligate biotrophic lifestyle. Additionally, the procedure could be applied for the selection of UVmutagenized fungal colonies with obvious changes in morphology or virulence spectrum, which could be correlated with mutations in the respective genome sequences via a genomewide association study. The method described here could also be adapted to other obligate biotrophic phytopathogens when

Table 4. Number of manually validated unique variants in Blumeria graminis f. sp. hordei isolates UV2D and UV8

\begin{tabular}{lccccc}
\hline & $\begin{array}{c}\text { Confirmed } \\
\text { variants } \\
\text { variants } \\
\text { after } \\
\text { filtered }\end{array}$ & $\begin{array}{c}\text { visualization } \\
\text { with IGV }\end{array}$ & $\begin{array}{c}\text { Variants } \\
\text { within } \\
\text { genes }\end{array}$ & $\begin{array}{c}\text { Variants } \\
\text { up- or } \\
\text { downstream } \\
\text { of genes }\end{array}$ & $\begin{array}{c}\text { Variants } \\
\text { in } \\
\text { intergenic } \\
\text { space }\end{array}$ \\
\hline UV2D & 325 & 125 & 24 & 49 & 52 \\
UV8 & 175 & 22 & 4 & 9 & 9 \\
\hline
\end{tabular}

a According to analysis with Freebayes.

b $\mathrm{IGV}=$ Integrated Genomics Viewer.

Table 5. Manually validated mutations corresponding to the canonical ultraviolet (UV) signature in UV2D and UV8

\begin{tabular}{lrcrc}
\hline Parameter & UV2D & Frequency & UV8 & Frequency \\
\hline Total mutations identified & 125 & & 22 & \\
Canonical UV signature SNPs & 57 & $46 \%$ & 11 & $50 \%$ \\
SNPs at di-pyrimidine sites & 56 & $98 \%$ & 8 & $72 \%$ \\
SNP C $\rightarrow$ T & 27 & & 5 & \\
SNP G $\rightarrow$ A & 30 & & 6 & \\
\hline
\end{tabular}

a $\mathrm{SNP}=$ single nucleotide polymorphisms. conventional methods for functional genomic profiling are not applicable.

\section{MATERIALS AND METHODS}

\section{Powdery mildew and plant material.}

The barley powdery mildew fungus $B$. graminis f. sp. hordei isolate K1 (Hinze et al. 1991) was used for the mutagenesis experiment. Propagation and recovery of $B$. graminis f. sp. hordei were performed on a spring barley cultivar (Hordeum vulgare variety Margret; I.G. Pflanzenzucht $\mathrm{GmbH}$, Ismaning, Germany), which is susceptible to B. graminis $\mathrm{f}$. $\mathrm{sp}$. hordei isolate $\mathrm{K} 1$. Additionally, for the virulence assay, barley lines P01 (Mlal [Kølster et al. 1986]) and BC Ingrid mlo-3 (Büschges et al. 1997) as well as the wheat variety KWS Sharki (KWS, Einbeck, Germany) were used. The barley seedlings in jars and the plants that served as a source for the detached leaves in plates were grown at $20^{\circ} \mathrm{C}$ with $16 \mathrm{~h}$ light $\left(78 \mu \mathrm{mol} \mathrm{s}^{-1}\right.$ $\mathrm{m}^{-2}$ ) and $8 \mathrm{~h}$ dark in a controlled growth cabinet.

\section{UV mutagenesis of $B$. graminis f. sp. hordei.}

Seven-day-old barley plants were inoculated with $B$. graminis $\mathrm{f}$. sp. hordei $\left(\mathrm{K} 1_{\text {Aachen }}\right)$ conidiospores. At 5 days after inoculation, the infected leaves were cut and were transferred to solid medium (1\% agar supplemented with $85 \mu \mathrm{M}$ benzimidazole) in petri dishes. Two days later, the detached leaves with the sporulating powdery mildew colonies on the agar plates were either not exposed to UV (control) or exposed to various periods of UV-C irradiation (254 nm wavelength for 10 or $30 \mathrm{~s}$ or $1,2,4,8$, or $12 \mathrm{~min}$ ) in a UV BIO-LINK crosslinker BLX254 (Vilber Lourmant, France). The total amount of UV energy generated inside the internal UV chamber per minute was $0.2 \mathrm{~J}$ (dimensions of the chamber were $14.5 \mathrm{~cm}$ height, $33 \mathrm{~cm}$ depth, and $26 \mathrm{~cm}$ width), resulting in approximately $2.3 \mathrm{~J} \mathrm{~min}^{-1} \mathrm{~m}^{-2}$. After UV treatment, fungal colonies were either kept on leaves in the dark for about another $18 \mathrm{~h}$ or were immediately used as inoculum on fresh barley plants cultivated on soil inside jars covered with gauze, to prevent the undesired dispersal of spores and also to prevent any contamination from outside. Similarly, fungal colonies from dark-incubated leaves were used as inoculum for fresh barley plants the next day. New B. graminis $\mathrm{f}$. sp. hordei colonies were allowed to develop for 5 days on the barley plants in the jars and, thereafter, leaves were cut and were transferred to $1 \%$ agar plates for evaluation of the number and phenotype of the colonies. Two days later, the next round of UV mutagenesis was carried out as described above (Fig. 1).

\section{Phenotypic characterization of mutant isolates.}

Individual B. graminis f. sp. hordei colonies were photographed with a stereo microscope at 7 days postinoculation of the susceptible cultivar Margret. For the assessment of entry rates, leaves of 7-day-old plants were inoculated with the various $B$. graminis $\mathrm{f}$. sp. hordei isolates ( $\mathrm{K} 1_{\text {Aachen }}, \mathrm{UV} 2 \mathrm{D}, \mathrm{UV} 8$ ) and were fixed at $48 \mathrm{~h}$ postinoculation in $80 \%$ ethanol. Fungal structures were stained with Coomassie brilliant blue (Carl Roth, Karlsruhe, Germany; $0.6 \%$ in ethanol) for a few seconds prior to observation by light microscopy. Entry rates were calculated as the percentage of germinated fungal conidia that permitted formation of a microcolony.

\section{DNA extraction and sequencing.}

The effect of UV mutagenesis for two exemplary B. graminis f. sp. hordei colonies retrieved from UV mutagenesis was assessed. One colony each from the experimental branch with dark incubation (seventh round, 2 min UV exposure, termed UV2D) and one colony from the experimental branch without dark incubation (sixth round, 8 min UV exposure, termed UV8) 
were selected. Fungal biomass of these single-spore isolates (each B. graminis f. sp. hordei colony results from a single spore) was further enriched by several rounds of clonal propagation on barley plants grown on soil in jars, as described above. Conidiospores of these single spore isolates were collected by aspiration with a vacuum device equipped with suitable filters, genomic DNA was extracted via the CTAB method (Spanu et al. 2010), and the extracted high-molecular weight genomic DNA purified using AMPure XP magnetic beads (Beckman Coulter, Brea, CA, U.S.A.) according to manufacturer instructions. The same procedure was followed to collect conidiospores and extract high-molecular weight DNA from the wild-type $B$. graminis $\mathrm{f}$. sp. hordei $\mathrm{K} 1_{\text {Aachen }}$ strain. A total amount of about $500 \mathrm{ng}$ of high-molecular weight genomic DNA was subjected to Illumina sequencing (performed at CEGAT GmbH, Tübingen, Germany; $2 \times 150$-bp read length, approximately $75 \times$ coverage, sequencing on NovaSeq 6000 ).

\section{Variant calling pipelines.}

The Illumina DNA sequence reads obtained during this work by sequencing the two mutant strains (UV2D and UV8) and the parental B. graminis f. sp. hordei $\mathrm{K} 1$ strain $\left(\mathrm{K} 1_{\text {Aachen }}\right)$, in addition to the already published DH14 reads (Frantzeskakis et al. $2018 \mathrm{~b}$ ) and the $\mathrm{K} 1$ reads $\left(\mathrm{K} 1_{\text {Cologne }}\right)$ obtained previously (Hacquard et al. 2013) were first quality-trimmed using Trimmomatic (Bolger et al. 2014). To ensure the sequencing reads were of sufficiently high quality, we performed an initial quality check of the sequence data using FastQC. Subsequently, the reads were mapped to the $B$. graminis $\mathrm{f}$. sp. hordei DH14 genome assembly (Frantzeskakis et al. 2018b; Spanu et al. 2010) using BWA-MEM (Li and Durbin 2009). The resulting bam file was sorted and polymerase chain reaction (PCR) duplicates were marked using Picard tools. Afterward, the raw variants were called from the sorted bam file by using three different tools, which are the mpileup function in the SAMtools toolkit (Li et al. 2009), FreeBayes (Garrison and Marth 2012), and GATK-HaplotypeCaller (McKenna et al. 2010). Then, bcftools (Li 2011) was used to keep only the unique SNPs in either UV2D (not present in UV8) or UV8 (not present in UV2D). In addition, bcftools was used to compare $\mathrm{K} 1_{\text {Cologne }}$ and $\mathrm{K} 1_{\text {Aachen. }}$. Filtering the variants to keep only the high confidence variants was done using SnpSift (Cingolani et al. 2012a), VCFtools (Danecek et al. 2011), and GATK (McKenna et al. 2010) for the three variant calling tools mentioned before, respectively. The effects of the identified variants were predicted using the SnpEff tool (Cingolani et al. 2012b). Finally, all identified unique SNPs were visualized and were manually evaluated via IGV (Thorvaldsdóttir et al. 2013). In addition, the common variants between UV2D and UV8 were analyzed to examine whether there are any UV mutagenesis hotspots in the $B$. graminis f. sp. hordei genome. To this end, first the unique variants in UV2D or UV8 (not present in $\mathrm{K} 1_{\text {Aachen }}$ ) were called using bcftools ( $\mathrm{Li}$ 2011). Then, the variants that are common between these two unique variant lists were identified using the same tool. The variants were then filtered using VCFtools (Danecek et al. 2011). Finally, all identified common variants were visualized and manually evaluated via the IGV (Thorvaldsdóttir et al. 2013). The bash script used for this analysis can be found in GitHub.

\section{Calculation of SNP frequencies.}

The SNPs occurring inside or up- or downstream of singlecopy genes were first extracted from the raw vcf files of $\mathrm{K} 1_{\text {Cologne, }}, \mathrm{K} 1_{\text {Aachen }}$, and DH14. Next, the positions of the SNPs, the read depth at each SNP, and the number of reads supporting the alternative allele were retrieved from the generated singlecopy gene vcf file using the GATK tool. These data were then used to calculate the percentage of reads supporting each of the SNPs and to establish a PivotTable, from which the SNP frequency histograms were generated. The bash script used for this analysis can be found on GitHub.

\section{ACKNOWLEDGMENTS}

We thank A. Reinstädler for excellent technical assistance regarding the maintenance of powdery mildew isolates and T. Bolger for helpful discussions concerning bioinformatic analysis. The analysis was performed with computing resources granted by RWTH Aachen University under project ID rwth0146.

\section{AUTHOR-RECOMMENDED INTERNET RESOURCES}

FastQC: https://www.bioinformatics.babraham.ac.uk/projects/fastqc

GitHub scripts: https://github.com/MirnaBarsoum/UV_mutagenesis_BghK1-/blob/master/Scripts_Variant_Calling.md

IGV alignment track: https://software.broadinstitute.org/software/igv/ PopupMenus\#AlignmentTrack

Picard tools: http://broadinstitute.github.io/picard

\section{NOTE ADDED IN PROOF}

Shortly after acceptance of this manuscript (29 April 2020), we became aware of a study published in parallel (March 20, 2020, Li et al. 2020) that combines EMS mutagenesis of the wheat stripe rust pathogen Puccinia striiformis $\mathrm{f}$. sp. tritici with whole-genome re-sequencing and genome-wide association analysis, as suggested for the powdery mildew pathogen at the end of our discussion.

\section{LITERATURE CITED}

Abt, T. D., Souffriau, B., Foulquié-Moreno, M. R., Duitama, J., and Thevelein, J. M. 2016. Genomic saturation mutagenesis and polygenic analysis identify novel yeast genes affecting ethyl acetate production, a non-selectable polygenic trait. Microb. Cell 3:159-175.

Ahmed, A. A., Pedersen, C., Schultz-Larsen, T., Kwaaitaal, M., Jørgensen, H. J., and Thordal-Christensen, H. 2015. The barley powdery mildew candidate secreted effector protein CSEP0105 inhibits the chaperone activity of a small heat shock protein. Plant Physiol. 168:321-333.

Barsoum, M., Sabelleck, B. D., Spanu, P., and Panstruga, R. 2019. Rumble in the effector jungle: Candidate effector proteins in interactions of plants with powdery mildew and rust fung. Crit. Rev. Plant Sci. 38: 255-279.

Ben-Amar, A., Daldoul, S., Reustle, G. M., Krczal, G., and Mliki, A. 2016 Reverse genetics and high throughput sequencing methodologies for plant functional genomics. Curr. Genomics 17:460-475.

Bobay, L.-M., Traverse, C. C., and Ochman, H. 2015. Impermanence of bacterial clones. Proc. Natl. Acad. Sci. U.S.A. 112:8893-8900.

Bolger, A. M., Lohse, M., and Usadel, B. 2014. Trimmomatic: A flexible trimmer for Illumina sequence data. Bioinformatics 30:2114-2120.

Bourras, S., Kunz, L., Xue, M., Praz, C. R., Müller, M. C., Kälin, C., Schläfli, M., Ackermann, P., Flückiger, S., Parlange, F., Menardo, F., Schaefer, L. K., Ben-David, R., Roffler, S., Oberhaensli, S., Widrig, V., Lindner, S., Isaksson, J., Wicker, T., Yu, D., and Keller, B. 2019. The AvrPm3-Pm3 effector-NLR interactions control both race-specific resistance and hostspecificity of cereal mildews on wheat. Nat. Commun. 10:2292.

Bourras, S., McNally, K. E., Ben-David, R., Parlange, F., Roffler, S., Praz, C. R., Oberhaensli, S., Menardo, F., Stirnweis, D., Frenkel, Z., Schaefer, L. K., Flückiger, S., Treier, G., Herren, G., Korol, A. B., Wicker, T., and Keller, B. 2015. Multiple avirulence loci and allele-specific effector recognition control the $P m 3$ race-specific resistance of wheat to powdery mildew. Plant Cell 27:2991-3012.

Braun, U., and Cook, R. T. A. 2012. Taxonomic manual of the Erysiphales (powdery mildews). CBS biodiversity series 11. CBS-KNAW Fungal Biodiversity Center, Utrecht, The Netherlands.

Brefort, T., Tanaka, S., Neidig, N., Doehlemann, G., Vincon, V., and Kahmann, R. 2014. Characterization of the largest effector gene cluster of Ustilago maydis. PLoS Pathog. 10:e1003866.

Büschges, R., Hollricher, K., Panstruga, R., Simons, G., Wolter, M., Frijters, A., van Daelen, R., van der Lee, T., Diergaarde, P., Groenendijk, J., Töpsch, S., Vos, P., Salamini, F., and Schulze-Lefert, P. 1997. The barley Mlo gene: A novel control element of plant pathogen resistance. Cell 88:695-705. 
Cingolani, P., Patel, V. M., Coon, M., Nguyen, T., Land, S. J., Ruden, D. M., and Lu, X. 2012a. Using Drosophila melanogaster as a model for genotoxic chemical mutational studies with a new program, SnpSift. Front. Genet. 3:35

Cingolani, P., Platts, A., Wang, L., Coon, M., Nguyen, T., Wang, L., Land S. J., Lu, X., and Ruden, D. M. 2012b. A program for annotating and predicting the effects of single nucleotide polymorphisms, SnpEff: SNPs in the genome of Drosophila melanogaster strain $w^{1118} ;$ iso-2; iso-3. Fly (Austin) 6:80-92.

Danecek, P., Auton, A., Abecasis, G., Albers, C. A., Banks, E., DePristo, M. A., Handsaker, R. E., Lunter, G., Marth, G. T., Sherry, S. T., McVean, G., Durbin, R., and 1000 Genomes Project Analysis Group. 2011. The variant call format and VCFtools. Bioinformatics 27:2156-2158.

Dean, R., Van Kan, J. A. L., Pretorius, Z. A., Hammond-Kosack, K. E., Di Pietro, A., Spanu, P. D., Rudd, J. J., Dickman, M., Kahmann, R., Ellis, J., and Foster, G. D. 2012. The top 10 fungal pathogens in molecular plant pathology. Mol. Plant Pathol. 13:414-430.

Delventhal, R., Rajaraman, J., Stefanato, F. L., Rehman, S., Aghnoum, R., McGrann, G. R. D., Bolger, M., Usadel, B., Hedley, P. E., Boyd, L., Niks, R. E., Schweizer, P., and Schaffrath, U. 2017. A comparative analysis of nonhost resistance across the two Triticeae crop species wheat and barley. BMC Plant Biol. 17:232.

Frantzeskakis, L., Di Pietro, A., Rep, M., Schirawski, J., Wu, C.-H., and Panstruga, R. 2020. Rapid evolution in plant-microbe interactions-A molecular genomics perspective. New Phytol. 225:1134-1142.

Frantzeskakis, L., Kracher, B., Kusch, S., Yoshikawa-Maekawa, M., Bauer, S., Pedersen, C., Spanu, P. D., Maekawa, T., Schulze-Lefert, P., and Panstruga, R. 2018b. Signatures of host specialization and a recent transposable element burst in the dynamic one-speed genome of the fungal barley powdery mildew pathogen. BMC Genomics 19:381.

Frantzeskakis, L., Kusch, S., and Panstruga, R. 2019. The need for speed: Compartmentalized genome evolution in filamentous phytopathogens. Mol. Plant Pathol. 20:3-7.

Frantzeskakis, L., von Dahlen, J. K., Panstruga, R., and Rose, L. E. 2018a. Rapid evolution in the tug-of-war between microbes and plants. New Phytol. 219:12-14.

Garrison, E., and Marth, G. 2012. Haplotype-based variant detection from short-read sequencing. arXiv 1207.3907v2. Published online.

Godfroy, O., Peters, A. F., Coelho, S. M., and Cock, J. M. 2015. Genomewide comparison of ultraviolet and ethyl methanesulphonate mutagenesis methods for the brown alga Ectocarpus. Mar. Genomics 24:109-113.

Hacquard, S., Kracher, B., Maekawa, T., Vernaldi, S., Schulze-Lefert, P., and Ver Loren van Themaat, E. 2013. Mosaic genome structure of the barley powdery mildew pathogen and conservation of transcriptional programs in divergent hosts. Proc. Natl. Acad. Sci. U.S.A. 110: E2219-E2228.

Hilton, L. K., Meili, F., Buckoll, P. D., Rodriguez-Pike, J. C., Choutka, C. P., Kirschner, J. A., Warner, F., Lethan, M., Garces, F. A., Qi, J., and Quarmby, L. M. 2016. A forward genetic screen and whole genome sequencing identify deflagellation defective mutants in Chlamydomonas, including assignment of ADF1 as a TRP channel. G3 (Bethesda) 6: 3409-3418.

Hinze, K., Thompson, R. D., Ritter, E., Salamini, F., and Schulze-Lefert, P. 1991. Restriction fragment length polymorphism-mediated targeting of the ml-o resistance locus in barley (Hordeum vulgare). Proc. Natl. Acad. Sci. U.S.A. 88:3691-3695.

Ikehata, H., and Ono, T. 2011. The mechanisms of UV mutagenesis. J. Radiat. Res. (Tokyo) 52:115-125.

Janisiewicz, W. J., Takeda, F., Nichols, B., Glenn, D. M., Jurick, W. M., II, and Camp, M. J. 2016. Use of low-dose UV-C irradiation to control powdery mildew caused by Podosphaera aphanis on strawberry plants. Can. J. Plant Pathol. 38:430-439.

Jones, L., Riaz, S., Morales-Cruz, A., Amrine, K. C. H., McGuire, B., Gubler, W. D., Walker, M. A., and Cantu, D. 2014. Adaptive genomic structural variation in the grape powdery mildew pathogen, Erysiphe necator. BMC Genomics 15:1081.

Kobayashi, K., Ehrlich, S. D., Albertini, A., Amati, G., Andersen, K. K., Arnaud, M., Asai, K., Ashikaga, S., Aymerich, S., Bessieres, P., Boland, F., Brignell, S. C., Bron, S., Bunai, K., Chapuis, J., Christiansen, L. C., Danchin, A., Débarbouille, M., Dervyn, E., Deuerling, E., Devine, K., Devine, S. K., Dreesen, O., Errington, J., Fillinger, S., Foster, S. J., Fujita, Y., Galizzi, A., Gardan, R., Eschevins, C., Fukushima, T., Haga, K., Harwood, C. R., Hecker, M., Hosoya, D., Hullo, M. F., Kakeshita, H., Karamata, D., Kasahara, Y., Kawamura, F., Koga, K., Koski, P., Kuwana, R., Imamura, D., Ishimaru, M., Ishikawa, S., Ishio, I., Le Coq, D., Masson, A., Mauël, C., Meima, R., Mellado, R. P., Moir, A., Moriya, S., Nagakawa, E., Nanamiya, H., Nakai, S., Nygaard, P., Ogura, M., Ohanan, T., O'Reilly, M., O’Rourke, M., Pragai, Z., Pooley, H. M.,
Rapoport, G., Rawlins, J. P., Rivas, L. A., Rivolta, C., Sadaie, A., Sadaie, Y., Sarvas, M., Sato, T., Saxild, H. H., Scanlan, E., Schumann, W., Seegers, J. F. M. L., Sekiguchi, J., Sekowska, A., Séror, S. J., Simon, M., Stragier, P., Studer, R., Takamatsu, H., Tanaka, T., Takeuchi, M., Thomaides, H. B., Vagner, V., van Dijl, J. M., Watabe, K., Wipat, A. Yamamoto, H., Yamamoto, M., Yamamoto, Y., Yamane, K., Yata, K., Yoshida, K., Yoshikawa, H., Zuber, U., and Ogasawara, N. 2003. Essential Bacillus subtilis genes. Proc. Natl. Acad. Sci. U.S.A. 100: 4678-4683.

Kølster, P., Munk, L., Stølen, O., and Løhde, J. 1986. Near-isogenic barley lines with genes for resistance to powdery mildew. Crop Sci. 26:903-907.

Li, H. 2011. A statistical framework for SNP calling, mutation discovery, association mapping and population genetical parameter estimation from sequencing data. Bioinformatics 27:2987-2993.

Li, H., and Durbin, R. 2009. Fast and accurate short read alignment with Burrows-Wheeler transform. Bioinformatics 25:1754-1760.

Li, H., Handsaker, B., Wysoker, A., Fennell, T., Ruan, J., Homer, N., Marth, G., Abecasis, G., and Durbin, R.; 1000 Genome Project Data Processing Subgroup. 2009. The Sequence Alignment/Map format and SAMtools. Bioinformatics 25:2078-2079.

Li, Y., Wang, M., See, D. R., and Chen, X. 2019. Ethyl-methanesulfonate mutagenesis generated diverse isolates of Puccinia striiformis $\mathrm{f}$. $\mathrm{sp}$ tritici, the wheat stripe rust pathogen. World J. Microbiol. Biotechnol. $35: 28$.

Li, Y., Xia, C., Wang, M., Yin, C., and Chen, X. 2020. Whole-genome sequencing of Puccinia striiformis $\mathrm{f}$. sp. tritici mutant isolates identifies avirulence gene candidates. BMC Genomics 21:247.

Lu, X., Kracher, B., Saur, I. M. L., Bauer, S., Ellwood, S. R., Wise, R., Yaeno, T., Maekawa, T., and Schulze-Lefert, P. 2016. Allelic barley MLA immune receptors recognize sequence-unrelated avirulence effectors of the powdery mildew pathogen. Proc. Natl. Acad. Sci. U.S.A. 113:E6486-E6495.

Maekawa, T., Kracher, B., Vernaldi, S., Ver Loren van Themaat, E., and Schulze-Lefert, P. 2012. Conservation of NLR-triggered immunity across plant lineages. Proc. Natl. Acad. Sci. U.S.A. 109:20119-20123.

Martínez-Cruz, J., Romero, D., de Vicente, A., and Pérez-García, A. 2017. Transformation of the cucurbit powdery mildew pathogen Podosphaera xanthii by Agrobacterium tumefaciens. New Phytol. 213:1961-1973.

McKenna, A., Hanna, M., Banks, E., Sivachenko, A., Cibulskis, K., Kernytsky, A., Garimella, K., Altshuler, D., Gabriel, S., Daly, M., and DePristo, M. A. 2010. The genome analysis toolkit: A MapReduce framework for analyzing next-generation DNA sequencing data. Genome Res. 20:1297-1303.

Mohanta, T. K., and Bae, H. 2015. The diversity of fungal genome. Biol. Proced. Online 17:8.

Müller, M. C., Praz, C. R., Sotiropoulos, A. G., Menardo, F., Kunz, L., Schudel, S., Oberhänsli, S., Poretti, M., Wehrli, A., Bourras, S., Keller, B., and Wicker, T. 2019. A chromosome-scale genome assembly reveals a highly dynamic effector repertoire of wheat powdery mildew. New Phytol. 221:2176-2189.

Nguyen Ba, A. N., Cvijović, I., Rojas Echenique, J. I., Lawrence, K. R., Rego-Costa, A., Liu, X., Levy, S. F., and Desai, M. M. 2019. Highresolution lineage tracking reveals travelling wave of adaptation in laboratory yeast. Nature 575:494-499.

Nowara, D., Gay, A., Lacomme, C., Shaw, J., Ridout, C., Douchkov, D., Hensel, G., Kumlehn, J., and Schweizer, P. 2010. HIGS: Host-induced gene silencing in the obligate biotrophic fungal pathogen Blumeria graminis. Plant Cell 22:3130-3141.

Pedersen, C., Ver Loren van Themaat, E., McGuffin, L. J., Abbott, J. C., Burgis, T. A., Barton, G., Bindschedler, L. V., Lu, X., Maekawa, T., Wessling, R., Cramer, R., Thordal-Christensen, H., Panstruga, R., and Spanu, P. D. 2012. Structure and evolution of barley powdery mildew effector candidates. BMC Genomics 13:694.

Pennington, H. G., Jones, R., Kwon, S., Bonciani, G., Thieron, H., Chandler, T., Luong, P., Morgan, S. N., Przydacz, M., Bozkurt, T., Bowden, S., Craze, M., Wallington, E. J., Garnett, J., Kwaaitaal, M., Panstruga, R., Cota, E., and Spanu, P. D. 2019. The fungal ribonuclease-like effector protein CSEP0064/BEC1054 represses plant immunity and interferes with degradation of host ribosomal RNA. PLoS Pathog. 15:e1007620.

Pliego, C., Nowara, D., Bonciani, G., Gheorghe, D. M., Xu, R., Surana, P., Whigham, E., Nettleton, D., Bogdanove, A. J., Wise, R. P., Schweizer, P., Bindschedler, L. V., and Spanu, P. D. 2013. Host-induced gene silencing in barley powdery mildew reveals a class of ribonuclease-like effectors. Mol. Plant-Microbe Interact 26:633-642.

Potgieter, L., Feurtey, A., Dutheil, J. Y., and Stukenbrock, E. H. 2020. On variant discovery in genomes of fungal plant pathogens. Front. Microbiol. 11:626. 
Praz, C. R., Bourras, S., Zeng, F., Sánchez-Martín, J., Menardo, F., Xue, M., Yang, L., Roffler, S., Böni, R., Herren, G., McNally, K. E., Ben-David, R., Parlange, F., Oberhaensli, S., Flückiger, S., Schäfer, L. K., Wicker, T., Yu, D., and Keller, B. 2017. AvrPm2 encodes an RNase-like avirulence effector which is conserved in the two different specialized forms of wheat and rye powdery mildew fungus. New Phytol. 213:1301-1314.

Rastogi, R. P., Richa, Kumar, A., Tyagi, M. B., and Sinha, R. P. 2010. Molecular mechanisms of ultraviolet radiation-induced DNA damage and repair. J. Nucl. Acids 2010:592980.

Ribeiro, A., Golicz, A., Hackett, C. A., Milne, I., Stephen, G., Marshall, D., Flavell, A. J., and Bayer, M. 2015. An investigation of causes of false positive single nucleotide polymorphisms using simulated reads from a small eukaryote genome. BMC Bioinformatics 16:382.

Saur, I. M., Bauer, S., Kracher, B., Lu, X., Franzeskakis, L., Müller, M. C., Sabelleck, B., Kümmel, F., Panstruga, R., Maekawa, T., and SchulzeLefert, P. 2019. Multiple pairs of allelic MLA immune receptor-powdery mildew $\mathrm{AVR}_{\mathrm{A}}$ effectors argue for a direct recognition mechanism. eLife 8:e44471

Schmidt, S. M., Kuhn, H., Micali, C., Liller, C., Kwaaitaal, M., and Panstruga, R. 2014. Interaction of a Blumeria graminis f. sp. hordei effector candidate with a barley ARF-GAP suggests that host vesicle trafficking is a fungal pathogenicity target. Mol. Plant Pathol. 15:535-549.

Shapiro, B. J. 2016. How clonal are bacteria over time? Curr. Opin. Microbiol. 31:116-123.

Sherwood, J. E., Slutsky, B., and Somerville, S. C. 1991. Induced morphological and virulence variants of the obligate barley pathogen Erysiphe graminis f. sp. hordei. Phytopathology 81:1350-1357.

Sinha, R. P., and Häder, D. P. 2002. UV-induced DNA damage and repair: A review. Photochem. Photobiol. Sci. 1:225-236.

Spanu, P. D., Abbott, J. C., Amselem, J., Burgis, T. A., Soanes, D. M., Stüber, K., Ver Loren van Themaat, E., Brown, J. K. M., Butcher, S. A., Gurr, S. J., Lebrun, M. H., Ridout, C. J., Schulze-Lefert, P., Talbot, N. J., Ahmadinejad, N., Ametz, C., Barton, G. R., Benjdia, M., Bidzinski, P., Bindschedler, L. V., Both, M., Brewer, M. T., Cadle-Davidson, L., CadleDavidson, M. M., Collemare, J., Cramer, R., Frenkel, O., Godfrey, D., Harriman, J., Hoede, C., King, B. C., Klages, S., Kleemann, J., Knoll, D.,
Koti, P. S., Kreplak, J., López-Ruiz, F. J., Lu, X., Maekawa, T., Mahanil, S., Micali, C., Milgroom, M. G., Montana, G., Noir, S., O’Connell, R. J., Oberhaensli, S., Parlange, F., Pedersen, C., Quesneville, H., Reinhardt, R., Rott, M., Sacristán, S., Schmidt, S. M., Schön, M., Skamnioti, P., Sommer, H., Stephens, A., Takahara, H., Thordal-Christensen, H., Vigouroux, M., Wessling, R., Wicker, T., and Panstruga, R. 2010. Genome expansion and gene loss in powdery mildew fungi reveal tradeoffs in extreme parasitism. Science 330:1543-1546.

Suthaparan, A., Pathak, R., Solhaug, K. A., and Gislerød, H. R. 2018. Wavelength dependent recovery of UV-mediated damage: Tying up the loose ends of optical based powdery mildew management. J. Photochem. Photobiol. B 178:631-640.

Suthaparan, A., Solhaug, K. A., Stensvand, A., and Gislerød, H. R. 2016. Determination of UV action spectra affecting the infection process of Oidium neolycopersici, the cause of tomato powdery mildew. J. Photochem. Photobiol. B 156:41-49.

Thorvaldsdóttir, H., Robinson, J. T., and Mesirov, J. P. 2013. Integrative Genomics Viewer (IGV): High-performance genomics data visualization and exploration. Brief. Bioinform. 14:178-192.

Wang, Q., and Coleman, J. J. 2019. Progress and challenges: Development and implementation of CRISPR/Cas9 technology in filamentous fungi. Comput. Struct. Biotechnol. J. 17:761-769.

Wicker, T., Oberhaensli, S., Parlange, F., Buchmann, J. P., Shatalina, M., Roffler, S., Ben-David, R., Doležel, J., Šimková, H., Schulze-Lefert, P., Spanu, P. D., Bruggmann, R., Amselem, J., Quesneville, H., Ver Loren van Themaat, E., Paape, T., Shimizu, K. K., and Keller, B. 2013. The wheat powdery mildew genome shows the unique evolution of an obligate biotroph. Nat. Genet. 45:1092-1096.

Wu, Y., Ma, X., Pan, Z., Kale, S. D., Song, Y., King, H., Zhang, Q., Presley, C., Deng, X., Wei, C.-I., and Xiao, S. 2018. Comparative genome analyses reveal sequence features reflecting distinct modes of hostadaptation between dicot and monocot powdery mildew. BMC Genomics 19:705.

Zhu, Y. O., Siegal, M. L., Hall, D. W., and Petrov, D. A. 2014. Precise estimates of mutation rate and spectrum in yeast. Proc. Natl. Acad. Sci. U.S.A. 111:E2310-E2318. 